
\title{
25 Research Sourere \\ Incidence of heart valve disease in women treated with the ergot-derived dopamine agonist bromocriptine
}

\section{Marianne F. Clausen}

Rigshospitalet

Rasmus Rørth

Rigshospitalet

Christian Torp-Pedersen

Nordsjællands Hospital

Lucas Malta Westergaard

Rigshospitalet

Peter E. Weeke

Rigshospitalet

Gunnar Gislason

Gentofte Hospital

Lars Køber

Rigshospitalet

Emil Fosbøl

Rigshospitalet

Søren Lund Kristensen ( $\nabla$ slk@heart.dk)

Rigshospitalet

\section{Research Article}

Keywords: Bromocriptine, ergot-derived dopamine agonist, heart valve disease, hyperprolactinemia

Posted Date: February 22nd, 2021

DOl: https://doi.org/10.21203/rs.3.rs-184426/v1

License: (c) (i) This work is licensed under a Creative Commons Attribution 4.0 International License.

Read Full License

Version of Record: A version of this preprint was published at BMC Cardiovascular Disorders on December 1st, 2021. See the published version at https://doi.org/10.1186/s12872-021-02439-y. 


\section{Abstract \\ Background}

Ergot-derived dopamine agonists are thought to induce fibrotic changes in cardiac valve leaflets. We sought to determine the incidence of heart valve disease in women treated with bromocriptine compared with age and sex matched controls from the background population.

\section{Methods}

In nationwide Danish registries we identified female patients treated with bromocriptine in the period 1995-2018. Patients were included at date of second redeemed prescription and were matched 1:5 with controls from the background population based on age, sex and year of inclusion by use of incidence density sampling. The outcomes were hospital admission for or outpatient diagnosis of heart valve disease, and death as competing risk. Incidence rates, cumulative incidence curves, and adjusted coxproportional hazard models adjusted for cardiovascular risk factors were used to assess outcomes in bromocriptine users vs. controls.

\section{Results}

A total of 3035 female bromocriptine users and 15175 matched controls were included. Median age at inclusion was 32 years (Q1-Q3, 28-37 years). Both bromocriptine users and controls had few comorbidities and low use of concomitant pharmacotherapy. Within 10 years of follow-up, 11 patients $(0.34 \%, 95 \% \mathrm{Cl} 0.13 \%-0.55 \%)$ and 44 controls $(0.29 \%, 95 \% \mathrm{Cl} 0.20-0.37)$ met the primary endpoint of heart valve disease, $p=0.63$. The adjusted cox regression analysis yielded a hazard ratio of $0.96(95 \%$ confidence interval $(\mathrm{Cl}) 0.55-1.69, \mathrm{p}=0.89$ ).

\section{Conclusions}

Treatment initiation with ergot-derived dopamine agonist bromocriptine in younger women with few comorbidities, was associated with a low absolute long-term risk of heart valve disease, not significantly different from the risk in age and sex matched population controls. Thus, indicating a low clinical yield of pre-treatment echocardiographic screening in this patient population in accordance with current guidelines.

\section{Key Points}

- The ergot-derived dopamine agonist cabergoline are thought to induce fibrotic changes in valve leaflets. 
- Bromocriptine is perceived as a safe cardiovascular alternative to cabergoline, but the knowledge on which this is based is sparse.

- In our study the use of bromocriptine was not associated with an increased risk of heart valve disease relative to age and sex matched population controls.

- 10-year incidence of heart valve disease was low and did not differ between bromocriptine treated patients and controls; $0.34 \%(95 \% \mathrm{Cl} 0.13-0.55)$ vs $0.29 \%$ (95\% Cl 0.20-0.37), respectively $\mathrm{p}=0.63$.

\section{Background}

Ergot-derived dopamine agonists are thought to induce fibrotic changes in valve leaflets, causing thickening and stiffening of valves and thereby valve regurgitation (1). This pathophysiological link to an increased heart valve disease risk may represent a class effect, related to stimulation of serotonin receptors, including the 5-hydroxy-tryptamine 2B receptors (5-HT2B), which also are found in cardiac tissue, and subclinical heart valve disease has been described in patients treated with bromocriptine (25). Other ergot-derived dopamine agonists, such as cabergoline and pergolide, exert full agonistic activity on the 5-HT2B receptors whereas bromocriptine only shows partial agonistic activity $(2,6)$.

Ergot-derived dopamine agonists are in general considered safe for long-term treatment of hyperprolactinemia due to the lower doses used compared with the dosages given to patients with Parkinson's disease (7-11). However, echocardiographic screening for heart valve disease are currently recommended for patients with hyperprolactinemia at treatment initiation and periodically during cabergoline therapy due to a suggested increased prevalence of mild to moderate regurgitation in the tricuspid, aortic and mitral valves in these patients $(12,13)$. Previously, smaller studies have showed no signal of an association between bromocriptine and an increased incidence of heart valve disease, and bromocriptine is therefore perceived as a safe cardiovascular alternative to cabergoline with no need for echocardiographic screening $(8,12-14)$.

As bromocriptine is used frequently in an otherwise young and healthy, primarily female population, any correlation with an increased risk of heart valve disease is clinically important. We therefore examined the relation between bromocriptine use and heart valve disease in a nationwide Danish cohort with median follow-up of around 20 years.

\section{Methods}

\section{Data sources:}

Danish nationwide administrative registries were used to collect data at individual levels by use of a unique personal identification number which is assigned to all residents in Denmark. For this study, three nationwide registers were linked on an individual level to obtain information on all Danish residents aged 18 years or older and who had claimed prescriptions of bromocriptine between 1 July 1995 to 26th June 
2018. The Danish National Patient Register holds information about all admissions to Danish hospitals since 1978, and outpatients visits since 1990, including diagnoses coded according to the International Classification of Diseases, eighth edition (ICD-8) and ICD-10 and all procedures, surgeries included, are coded according to the Nordic Medico-Statistical Committee (NOMESCO) classification (15). The Danish National Prescription Registry, which holds information on all claimed prescriptions in Denmark since 1995, ensuring complete data on date of dispensing, strength of the tablets, number of pills dispensed and of cause the prescribed drug grouped according to the Anatomical Therapeutic Chemical (ATC) codes (16). And the civil register contains information about vital status of all Danish residents (17). Register-based studies in which individuals cannot be identified do not require ethical approval in Denmark.

\section{Study population:}

We included female patients aged 18 years or older treated with bromocriptine and matched controls identified from the background population. Men treated with bromocriptine were excluded due to different indications for treatment, older age at treatment initiation, and differences in clinical characteristics (18). Patients entered the study cohort when claiming a second prescription of bromocriptine with this date defining the study inclusion date. Each patient was matched by age and sex to 5 matched controls, and patients and controls were followed from index date until occurrence of the first of following events: hospitalization for heart valve disease or an outpatient contact with a heart valve diagnosis, death, or end of study period (31th June 2018). We excluded patients who prior to study entry, had a history of: heart valve disease, rheumatic heart disease, rheumatic fever, chronic heart failure, congenital heart and valve disease, endocarditis, carcinoid syndrome, Parkinson's disease, pergolide-, levodopa-, cabergoline-, quinagolide-use, or patients who had been treated with medications that may induce fibrosis (fenfluramine, dexfenfluramine, ergotamine) (19). To ensure patients were naive bromocriptine users, we excluded patients who claimed a prescription in the first half of 1995 (first year of full data coverage in the registry). All patients were individually risk set matched by age, sex and year of inclusion with 5 controls from the background population. In sensitivity analysis we restricted the population to patients who claimed five or more prescriptions with the date of the fifth prescription claim set as index date.

The majority of patients (82\%) had no prior in or outpatient hospital diagnosis of hyperprolactinaemia before initiating bromocriptine treatment. We had no access to patient charts from the general practitioner but we assume these patients were treated by their general practitioner as we included other in and out hospital diagnoses which could indicate bromocriptine treatment.

Comorbidities and concomitant pharmacotherapy were identified by assessing all hospital discharge codes prior to index and information on claimed prescriptions one year before index date. ICD, procedure, and ATC codes used in this study are listed in the Supplementary Appendix Table 1 and 2.

\section{Outcomes}


The primary outcome was development of heart valve disease as defined by an outpatient clinic visit or hospital admission with a diagnosis of heart valve disease or valvular heart surgery. As secondary outcomes we assessed the risk of valvular heart surgery as proxy for the severity of heart valve disease.

\section{Statistical analysis}

Baseline characteristics for bromocriptine-treated patients and the control cohort were described by use of numbers and percentages for categorical variables and medians and interquartile ranges for continuous variables. Differences between the bromocriptine group and controls were obtained by use of Chi-square test for categorical variables.

Cumulative incidence curves for heart valve disease, with death as a competing risk, were estimated, and differences between patients and control cohort were compared using Gray's test. Crude incidence rates were calculated. Cause-specific Cox regression were used to compare risk of heart valve disease between patients and the control cohort. Cox regression analyses were adjusted for age at index, year of inclusion and history of hypertension, ischemic heart disease, acute myocardial infarction and diabetes mellitus. The variables adjusted for were chosen based on clinical relevance and known prognostic importance in heart valve disease. The variable age and comorbidities (hypertension, ischemic heart disease, acute myocardial infarction and diabetes) were tested for interactions with the use of bromocriptine in relation to both outcomes and, unless stated otherwise, found absent. Interactions were considered significant if they yielded a p-value $<0.05$. Log (-log(survival)) curves were used to evaluate the proportional hazard assumption. The assumption of linearity of age was tested by including a variable of age squared.

Furthermore, the interaction between patients with and without an ICD-code for hyperprolactinemia in addition to use of bromocriptine were tested for all outcomes.

In a supplementary analysis, we calculated the accumulated dosage of claimed bromocriptine for patients with and without a heart valve disease diagnosis. Differences between the groups were obtained by use of Wilcoxons test.

Results were considered significant if $P<0.05$. The SAS statistical software package, version 9.4 (SAS Institute, Cary, North Carolina; USA) and R, version 3.5.0 (R development Core Team) were used for all analyses.

\section{Results}

\section{Baseline characteristics}

A total of 3035 female patients treated with bromocriptine between 1995 and 2018 were included in the study (Fig. 1) and matched with 15175 controls. Clinical characteristics of patients and the matched control cohort are summarized in Table 1. Median age at index was 32 years (Q1-Q3, 28-37 years) and 
both groups had few comorbidities and low use of pharmacotherapy. The bromocriptine treated patients were more likely to have prior hypertension (75 (2.5\%) vs $220(1.4 \%))$, diabetes (42 (1.4\%) vs $101(0.7 \%))$ and chronic obstructive lung disease $(21(0.7 \%)$ vs $42(0.3 \%))$ with p-values $<0.0001$, and patients were more frequent users of beta-blockers $(82(2.7 \%)$ vs $247(1.6 \%), \mathrm{P}<0.0001)$ and thiazides $(84(2.8 \%)$ vs $270(1.8 \%), P=0.0004)$.

\section{Heart valve disease}

The median follow-up for patients were 18.2 years (Q1-Q3, 14.7-20.7 years) vs 18.2 years (Q1-Q3, 14.820.8 years) for controls. During follow-up 16 of $3035(0.56 \%)$ patients and 91 of $15175(0.60 \%)$ controls were diagnosed with heart valve disease. The incidence rate of heart valve disease among patients treated with bromocriptine was 0.31 per 1000 patient years (PY) (95\% $\mathrm{Cl} 0.20-0.51)$ compared with 0.35 per $1000 \mathrm{PY}$ in the control cohort (95\% Cl 0.28-0.43).

The cumulative incidence of heart valve disease with the competing risk of death are shown in Fig. 2a and Fig. 2b. The 10-year incidence of heart valve disease was $0.34 \%(95 \% \mathrm{Cl} 0.13-0.55)$ for patients vs $0.29 \%$ (95\% Cl 0.20-0.37) for controls, while the 20-year incidence of heart valve disease was $0.61 \%$ $(95 \% \mathrm{Cl} 0.31-0.91)$ for patients and $0.70 \%(95 \% \mathrm{Cl} 0.55-0.85)$ for the control cohort $(\mathrm{p}=0.63)$.

Competing risk of death was $6.0 \%(95 \% \mathrm{Cl} 5.0-7.0)$ among patients treated with bromocriptine and 4.4 $\%(95 \% \mathrm{Cl} 4.0-4.8)$ for the control cohort, $p=0.002$.

The unadjusted cox regression model for the risk of heart valve disease in patients vs. controls yielded a hazard ratio (HR) of $1.06(95 \% \mathrm{Cl} 0.61-1.84, \mathrm{p}=0.85)$, and the adjusted analysis yielded a HR of 0.96 $(95 \% \mathrm{Cl} 0.55-1.69, \mathrm{p}=0.89)$.

\section{Heart valve surgery}

During the study period, 6 patients $(0.20 \%)$ and 16 controls $(0.11 \%)$ underwent heart valve surgery. The 20 -year incidence of heart valve surgery was $0.22 \%(95 \% \mathrm{Cl} 0.04-0.40)$ for patients and $0.11 \%(95 \% \mathrm{Cl}$ $0.05-0.18$ ) for the control cohort; $p=0.18$ (Fig. 3a). Competing risk of death was $6.2 \%$ (95\% Cl 5.2-7.2) among patients and $4.6 \%(95 \% \mathrm{Cl} 4.2-5.0)$ among controls; $p=0.003$ (Fig. 3b).

Unadjusted cox regression model for heart valve surgery yielded a HR of 2.05 (95\% Cl 0.78-5.43, p = $0.15)$, while adjusted analysis yielded a HR of 1.88 (95\% Cl $0.68-5.19, p=0.22)$, for those who initiated bromocriptine treatment vs matched controls.

\section{Diagnosis of hyperprolactinaemic disorders}

Of 3035 patients who initiated bromocriptine treatment, 544 (18\%) had a prior hospital discharge diagnosis of hyperprolactinaemia. We found no significant difference in the risk of heart valve disease between patients with and without a prior diagnosis $(p=0.51)$.

\section{Long-term use of bromocriptine}


In a sensitivity analysis, we identified 603 patients who claimed five or more bromocriptine prescriptions during follow-up. In this group, 5 patients $(0.83 \%)$ were diagnosed with heart valve disease, while 1 (0.17

$\%)$ patient underwent heart valve surgery. These patients were characterized by more comorbidity and use of pharmacotherapy at baseline (Table 2).

Unadjusted cox regression model for heart valve disease yielded a HR of $1.10(95 \% \mathrm{Cl} 0.37-3.25, \mathrm{P}=$ 0.87 ), while adjusted analysis yielded a HR of 0.71 (95\% $\mathrm{Cl} 0.21-2.4, \mathrm{P}=0.59)$, for patients claiming five or more bromocriptine prescriptions vs those claiming less than five prescriptions.

Patients that eventually were diagnosed with heart valve disease diagnosis $(n=16)$ claimed an accumulated median dosage of $275 \mathrm{mg}$ (Q1-Q3: 150-1456 mg) bromocriptine and patients without claimed an accumulated median dosage of $200 \mathrm{mg}$ (Q1-Q3: 150-525 mg) bromocriptine, $p=0.56$

\section{Discussion}

In this nationwide cohort study of women who initiated treatment with bromocriptine, we observed a low incidence of heart valve disease during long-term follow-up, that did not differ significantly compared to matched controls from the background population. In a sensitivity analysis of patients who claimed five or more prescriptions of bromocriptine, the absolute risk of heart valve disease was somewhat higher, which could suggest a dose-response association, even if incidence did not differ significantly compared to matched controls. Still, the absolute risk of heart valve disease remained low, and this patient group was also characterized by a higher prevalence of conventional risk factors for cardiovascular disease. Furthermore, bromocriptine treated women who eventually were diagnosed with heart valve disease did not receive higher accumulated dosage of claimed bromocriptine compared to those who did not.

To date, most research have focused on the risk of heart valve disease associated with the dopamine agonist cabergoline and only few studies have investigated bromocriptine. Prior to this raised awareness, cabergoline was more widely used in the treatment of hyperprolactinemia due to its better tolerability, therapeutic efficacy and dosage advantages (9). Previously, three smaller studies have not found any association between long-term bromocriptine-use and clinically significant heart valve disease $(13,14$, 20). Steffensen et al investigated the incidence of heart valve abnormalities in Danish patients with hyperprolactinemia irrespective of treatment. They found low incidence and no significant differences between patients $(0.80 \%)$ and controls $(0.31 \%)$ after a median of 16 years of follow-up (21). Thus, our knowledge regarding the association of bromocriptine use and heart valve disease in patients with hyperprolactinaemia is sparse and based on subgroups of few patients.

Another important finding of our study was a significantly higher mortality rate for patients with hyperprolactinemia than controls, not readily explained by heart valve disease incidence. The higher mortality observed could be related to the underlying disease, transsphenoidal surgery for pituitary adenomas, prolactin's many diverse functions (22) or unmeasured confounders. The same tendency with a higher all-cause but also cardiovascular mortality in hyperprolactinaemic patients has been reported previously. $(23,24)$. 
In our study, the 10-year incidence of heart valve disease and surgery was low in both bromocriptine treated patients and matched controls (Fig. 2a and 3a). Furthermore, previous studies found that heart valve regurgitation occurs not uncommonly in people with structurally normal hearts (25-28). In 1968, World Health Organization (WHO) published 10 principles that should be considered when making screening guidelines $(29,30)$. Taken together, we believe that the clinical yield of echocardiographic screening in bromocriptine-treated female patients is low, and our findings are in line with the recommendations of not screening these patients as stated in current European guidelines (12).

\section{Limitations}

The main limitations of the present study are the absence of important clinical variables, such as body mass index, smoking, left ventricular ejection fraction, and systolic blood pressure. Another potential limitation was the definition of disease based on prescriptions rather than diagnostic coding. To accommodate this, we performed sensitivity analysis comparing baseline characteristics and risk of heart valve disease of bromocriptine treated patients with and without a diagnosis of hyperprolactinaemia. Residual confounding or confounding by indication could as well be a limitation in our study.

\section{Conclusions}

Initiation of treatment with bromocriptine in younger and otherwise healthy women was not associated with an increased long-term risk of heart valve disease compared to age and sex-matched controls, although it was associated with an increased mortality. Our study suggests a low clinical yield of echocardiographic screening in bromocriptine treated women which is in accordance with current guidelines.

\section{Declarations}

Ethics approval and consent to participate: This study was conducted in accordance with the declaration of Helsinki and approved by the Institutional Review Board of the Capital Region of Denmark (approval number: P-2019-348) in accordance with the General Data Protection Regulation. Registry-based studies in which individuals cannot be identified do not require consent from the patients according to national Danish regulations. Data access was obtained through Statistics Denmark, which allows data access upon application for all research institutions based in Denmark. Foreign researchers can get access through an affiliation to a Danish authorized research institution.

Consent for publication: Not applicable.

Availability of data and materials: The datasets generated and/or analysed during the current study are not publicly available due to Danish national policy on availability of health care registers, but are available from the corresponding author on reasonable request.

Competing interest: none declared. 
Funding: None

Authors contribution:

Concept and design of the work: MFC, SLK, RR, LK

Data collection: MFC, SLK, RR

Data analysis and interpretation: MFC, RR, CTP, LMW, PW, GG, LK, ELF, SLK

Drafting the article: MFC, SLK

Critical revision of the article: CTP, LMW, PW, ELF, GG, LK

Final approval of the version to be published: MFC, RR, CTP, LMW, PW, GG, LK, ELF, SLK

Acknowledgments: None.

\section{References}

1. Hutcheson JD, Setola V, Roth BL, Merryman WD. Serotonin receptors and heart valve disease-it was meant 2B. Pharmacology \& therapeutics. 2011;132(2):146-57.

2. Goldberg E, Grau JB, Fortier JH, Salvati E, Levy RJ, Ferrari G. Serotonin and catecholamines in the development and progression of heart valve diseases. Cardiovascular research. 2017;113(8):84957.

3. Kars M, Delgado V, Holman ER, Feelders RA, Smit JW, Romijn JA, et al. Aortic valve calcification and mild tricuspid regurgitation but no clinical heart disease after 8 years of dopamine agonist therapy for prolactinoma. J Clin Endocrinol Metab. 2008;93(9):3348-56.

4. Serratrice J, Disdier P, Habib G, Viallet F, Weiller PJ. Fibrotic valvular heart disease subsequent to bromocriptine treatment. Cardiol Rev. 2002;10(6):334-6.

5. Yarman S, Kurtulmus N, Bilge A. Optimal effective doses of cabergoline and bromocriptine and valvular leasions in men with prolactinomas. Neuro Endocrinol Lett. 2012;33(3):340-6.

6. Kvernmo T, Hartter S, Burger E. A review of the receptor-binding and pharmacokinetic properties of dopamine agonists. Clinical therapeutics. 2006;28(8):1065-78.

7. Auriemma RS, Grasso LF, Pivonello R, Colao A. The safety of treatments for prolactinomas. Expert opinion on drug safety. 2016;15(4):503-12.

8. Trifiro G, Mokhles MM, Dieleman JP, van Soest EM, Verhamme K, Mazzaglia G, et al. Risk of cardiac valve regurgitation with dopamine agonist use in Parkinson's disease and hyperprolactinaemia: a multi-country, nested case-control study. Drug safety. 2012;35(2):159-71.

9. Capozzi A, Scambia G, Pontecorvi A, Lello S. Hyperprolactinemia: pathophysiology and therapeutic approach. Gynecological endocrinology: the official journal of the International Society of 
Gynecological Endocrinology. 2015;31(7):506-10.

10. Oertel WH, Berardelli A, Bloem BR, Bonuccelli U, Burn D, Deuschl G, et al. Early (Uncomplicated) Parkinson's Disease. European Handbook of Neurological Management, Volume 1, Second EditionSep. 2010.

11. Patel T, Chang F. Parkinson's disease guidelines for pharmacists. Can Pharm J (Ott). 2014;147(3):161-70.

12. Melmed S, Casanueva FF, Hoffman AR, Kleinberg DL, Montori VM, Schlechte JA, et al. Diagnosis and treatment of hyperprolactinemia: an Endocrine Society clinical practice guideline. The Journal of clinical endocrinology and metabolism. 2011;96(2):273-88.

13. Boguszewski CL, dos Santos CM, Sakamoto KS, Marini LC, de Souza AM, Azevedo M. A comparison of cabergoline and bromocriptine on the risk of valvular heart disease in patients with prolactinomas. Pituitary. 2012;15(1):44-9.

14. Elenkova A, Shabani R, Kalinov K, Zacharieva S. Increased prevalence of subclinical cardiac valve fibrosis in patients with prolactinomas on long-term bromocriptine and cabergoline treatment. European journal of endocrinology. 2012;167(1):17-25.

15. Schmidt M, Schmidt SA, Sandegaard JL, Ehrenstein V, Pedersen L, Sorensen HT. The Danish National Patient Registry: a review of content, data quality, and research potential. Clinical epidemiology. 2015;7:449-90.

16. Kildemoes HW, Sorensen HT, Hallas J. The Danish National Prescription Registry. Scand J Public Health. 2011;39(7 Suppl):38-41.

17. Pedersen CB. The Danish Civil Registration System. Scand J Public Health. 2011;39(7 Suppl):22-5.

18. Arasho BD, Schaller B, Sandu N, Zenebe G. Gender-related differences in pituitary adenomas. Experimental and clinical endocrinology \& diabetes: official journal, German Society of Endocrinology [and] German Diabetes Association. 2009;117(10):567-72.

19. Bhattacharyya S, Schapira AH, Mikhailidis DP, Davar J. Drug-induced fibrotic valvular heart disease. Lancet (London, England). 2009;374(9689):577-85.

20. Halperin I, Aller J, Varela C, Mora M, Abad A, Doltra A, et al. No clinically significant valvular regurgitation in long-term cabergoline treatment for prolactinoma. Clinical endocrinology. 2012;77(2):275-80.

21. Steffensen C, Maegbaek ML, Laurberg P, Andersen M, Kistorp CM, Norrelund $H$, et al. Heart valve disease among patients with hyperprolactinemia: a nationwide population-based cohort study. The Journal of clinical endocrinology and metabolism. 2012;97(5):1629-34.

22. Marano RJ, Ben-Jonathan N. Minireview: Extrapituitary prolactin: an update on the distribution, regulation, and functions. Molecular endocrinology (Baltimore, Md). 2014;28(5):622-33.

23. Haring R, Friedrich N, Volzke H, Vasan RS, Felix SB, Dorr M, et al. Positive association of serum prolactin concentrations with all-cause and cardiovascular mortality. European heart journal. 2014;35(18):1215-21. 
24. Krogh J, Selmer C, Torp-Pedersen C, Gislason GH, Kistorp C. Hyperprolactinemia and the Association with All-Cause Mortality and Cardiovascular Mortality. Hormone and metabolic research $=$ Hormonund Stoffwechselforschung $=$ Hormones et metabolisme. 2017;49(6):411-7.

25. Singh JP, Evans JC, Levy D, Larson MG, Freed LA, Fuller DL, et al. Prevalence and clinical determinants of mitral, tricuspid, and aortic regurgitation (the Framingham Heart Study). The American journal of cardiology. 1999;83(6):897-902.

26. Choong CY, Abascal VM, Weyman J, Levine RA, Gentile F, Thomas JD, et al. Prevalence of valvular regurgitation by Doppler echocardiography in patients with structurally normal hearts by twodimensional echocardiography. American heart journal. 1989;117(3):636-42.

27. Nkomo VT, Gardin JM, Skelton TN, Gottdiener JS, Scott CG, Enriquez-Sarano M. Burden of valvular heart diseases: a population-based study. Lancet (London, England). 2006;368(9540):1005-11.

28. Stefano G, Fox K, Schluchter M, Hoit BD. Prevalence of unsuspected and significant mitral and aortic regurgitation. Journal of the American Society of Echocardiography: official publication of the American Society of Echocardiography. 2008;21(1):38-42.

29. Wilson JMG, Jungner G. Principles and practice of screening for disease. Geneva: World Health Organization. 1968.

30. Andermann A, Blancquaert I, Beauchamp S, Dery V. Revisiting Wilson and Jungner in the genomic age: a review of screening criteria over the past 40 years. Bulletin of the World Health Organization. 2008;86(4):317-9.

\section{Tables}

Due to technical limitations, Table 1 and Table 2 are only available as a download in the supplementary files section.

\section{Figures}




\section{Selection of population}

Patients in the Danish National Precription Registry claiming two or more precriptions of Bromocriptine, ATCcode: N04BC01 or B02CB01 between 1995 and 2018

$$
\mathrm{n}=5112
$$

\section{Excluded:}

Age $<18(n=26)$

Male gender $(n=780)$

Parkinson's Disease $(n=348)$

Rheumatic heart diseases $(n=3)$

Rheumatic fever $(n=1)$

Non-rheumatic valvular heart diseases $(n=13)$

Cardiomyopathies and rupture of chordae tendinae $(n=3)$

Chronic heart failure $(n=8)$

Endocarditis $(\mathrm{n}=0)$

Fibrosis-inducing drugs or one of following: cabergoline, quinagolide or levodopa $(n=449)$

"Wash-out-period" in first half of $1995(n=441)$

Missing data $(n=5)$

Final Bromocriptine cohort

$$
\mathrm{n}=\mathbf{3 0 3 5}
$$

\section{Figure 1}

Flow chart displaying patient selection.

Figure 2a

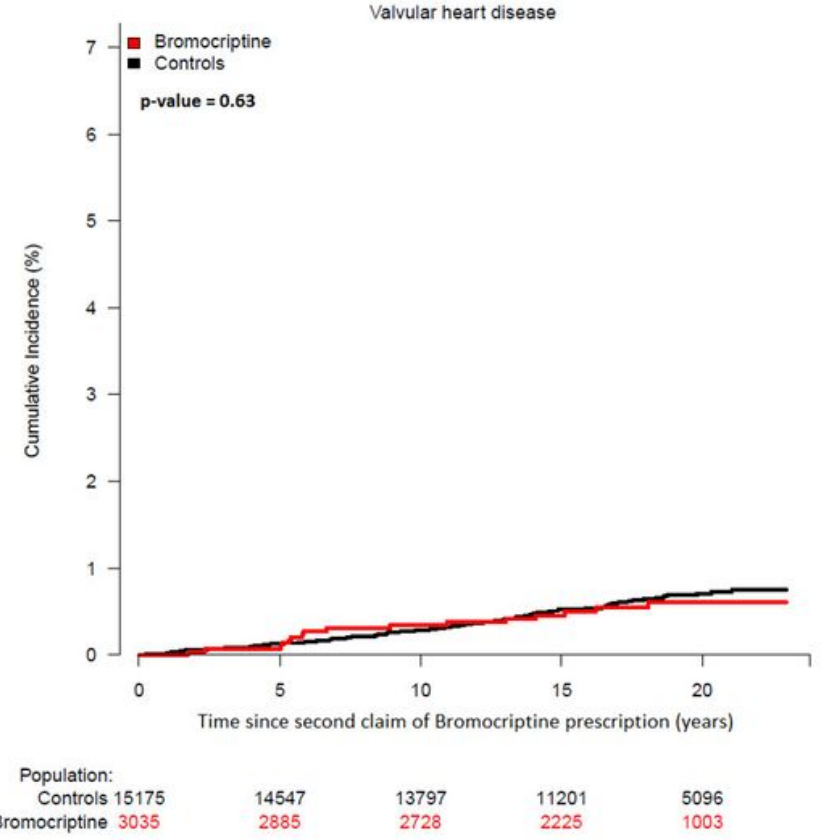

Figure $2 b$

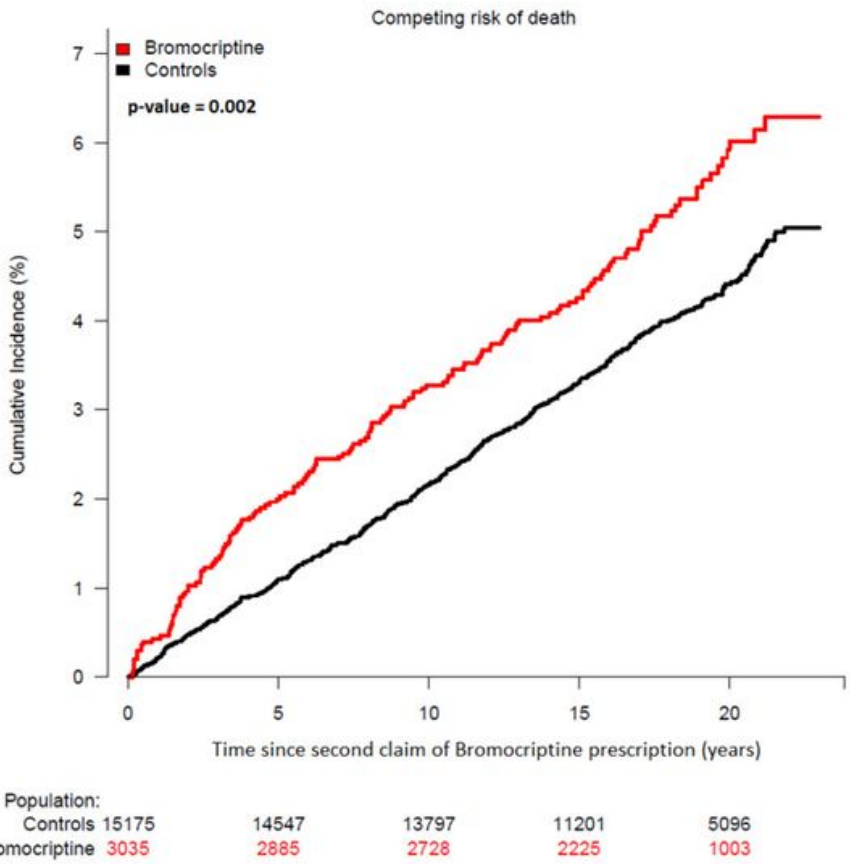


Figure 2

a. Cumulative incidence of valvular heart disease with death as a competing risk among bromocriptinetreated patients and matched controls. b. Cumulative incidence of competing risk of death among bromocriptine-treated patients and matched controls.

Figure 3a

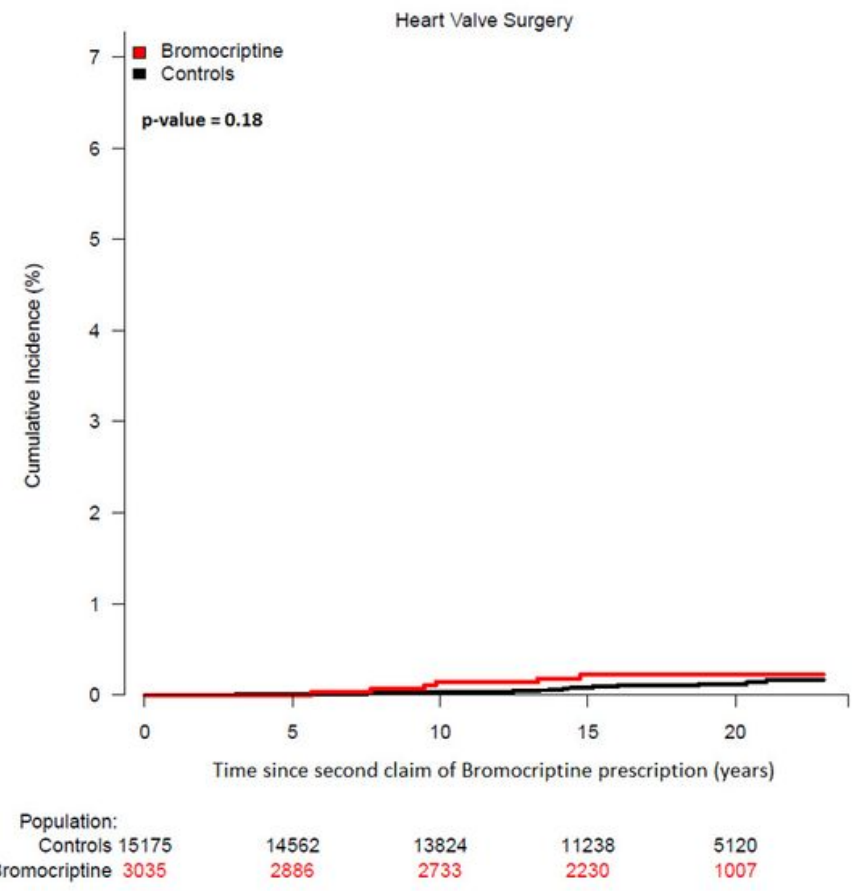

Figure 3b

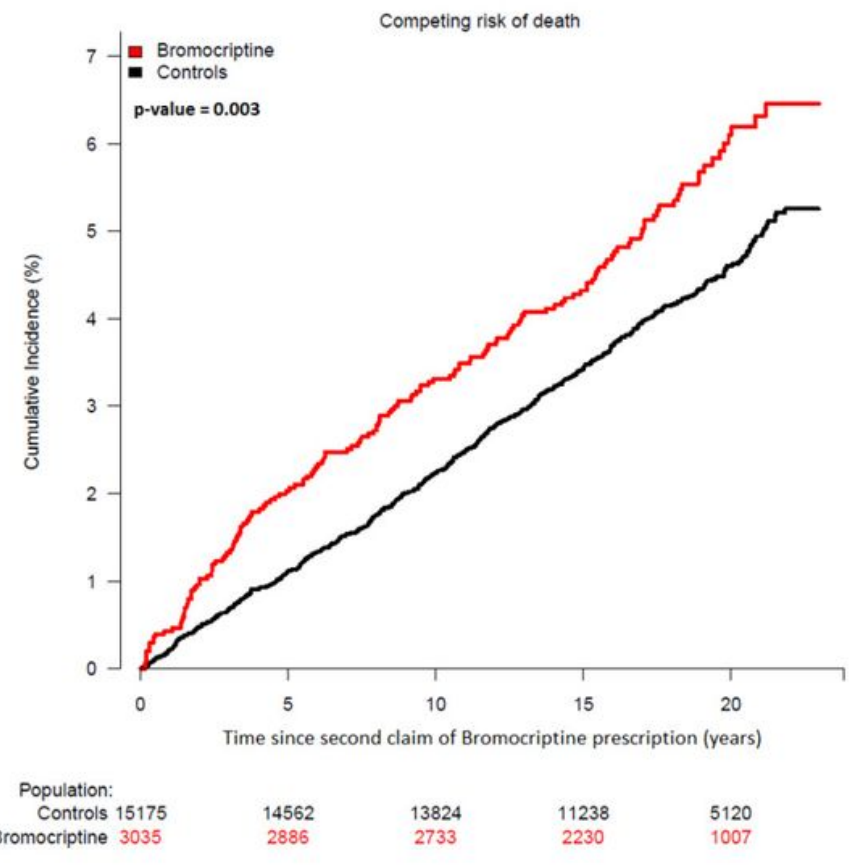

Figure 3

a. Cumulative incidence of heart valve surgery among bromocriptine-treated patients and matched controls. b. Cumulative incidence of competing risk of death among bromocriptine-patients and matched controls

\section{Supplementary Files}

This is a list of supplementary files associated with this preprint. Click to download.

- Supplementaryappendix.docx

- Tables.docx 